\title{
Common metabolic constraints on dive duration in endothermic and ectothermic vertebrates
}

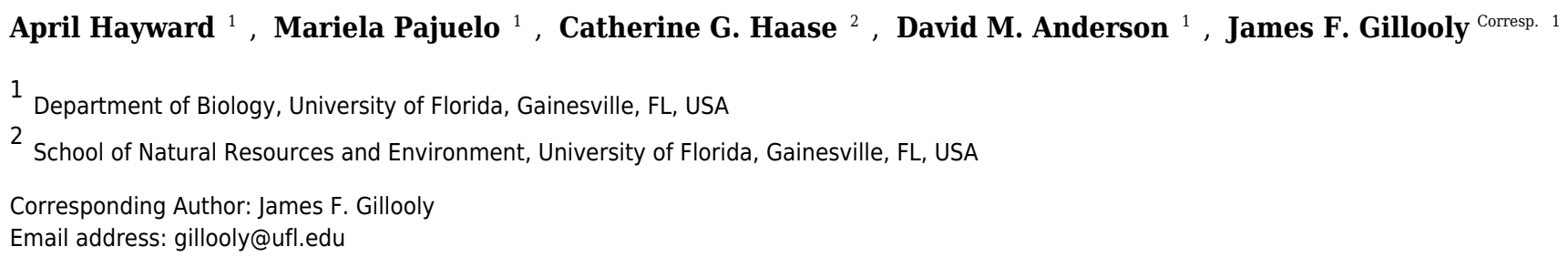

Dive duration in air-breathing vertebrates is thought to be constrained by the volume of oxygen stored in the body and the rate at which it is consumed (i.e., "oxygen store/usage hypothesis"). The body mass-dependence of dive duration among endothermic vertebrates is largely supportive of this model, but previous analyses of ectothermic vertebrates show no such body mass-dependence. Here we show that dive duration in both endotherms and ectotherms largely support the oxygen store/usage hypothesis after accounting for the well-established effects of temperature on oxygen consumption rates. Analyses of the body mass and temperature dependence of dive duration in 181 species of endothermic vertebrates and 29 species of ectothermic vertebrates show that dive duration increases as a power law with body mass, and decreases exponentially with increasing temperature. Thus, in the case of ectothermic vertebrates, changes in environmental temperature will likely impact the foraging ecology of divers. 
April Hayward ${ }^{1}$, Mariela Pajuelo ${ }^{1}$, Catherine G. Haase ${ }^{2}$, David M. Anderson ${ }^{1}$ and James F. Gillooly ${ }^{1,3}$

$20{ }^{1}$ Department of Biology University of Florida, Gainesville, FL 32611 USA

$21{ }^{2}$ School of Natural Resources and Environment, University of Florida, Gainesville, FL 32611

22 USA

$23{ }^{3}$ Corresponding Author: 352-392-2743, gillooly@ufl.edu 


\section{Abstract}

26 Dive duration in air-breathing vertebrates is thought to be constrained by the volume of oxygen

27 stored in the body and the rate at which it is consumed (i.e., "oxygen store/usage hypothesis").

28 The body mass-dependence of dive duration among endothermic vertebrates is largely

29 supportive of this model, but previous analyses of ectothermic vertebrates show no such body

30 mass-dependence. Here we show that dive duration in both endotherms and ectotherms largely

31 support the oxygen store/usage hypothesis after accounting for the well-established effects of

32 temperature on oxygen consumption rates. Analyses of the body mass and temperature

33 dependence of dive duration in 181 species of endothermic vertebrates and 29 species of

34 ectothermic vertebrates show that dive duration increases as a power law with body mass, and

35 decreases exponentially with increasing temperature. Thus, in the case of ectothermic

36 vertebrates, changes in environmental temperature will likely impact the foraging ecology of

37 divers.

38 Key Words: diving behavior, metabolic theory, metabolism, thermal ecology, oxygen storage,

39 allometry, scaling 
41

42

43

44

45

46

47

\section{Introduction}

The length of time that air-breathing vertebrate divers can remain submerged is an

important constraint on their foraging activities, and perhaps ultimately on their fitness (Butler \& Jones 1982; Kooyman 1989; Stephens et al. 2008; Andrews \& Enstipp 2016). Consequently, vertebrates display a wide variety of behavioral, morphological, and physiological adaptations to enhance dive capacity. For example, endothermic vertebrates that dive show a relatively high capacity to store oxygen, use anaerobic metabolism, and reduce oxygen demand in non-vital tissues to prolong dive duration (Boyd 1997; Butler \& Jones 1997; Kooyman \& Ponganis 1998). For example, with respect to oxygen storage, cetaceans have higher densities of myoglobin in their tissues of a molecular form that has evolved to be more stable at depth (Mirceta et al. 2013). Despite such specialization, maximum dive duration in endotherms varies somewhat predictably with body mass based on the amount of oxygen stored in the body and the rate at which oxygen is consumed (Butler \& Jones 1982; Schreer et al. 1997; Halsey et al. 2006a; Halsey et al. 2006b; Stephens et al. 2008). However, the extent to which dive duration may similarly vary with body mass in ectotherms as predicted by the oxygen store/usage hypothesis is less clear. Recent studies concluded that ectotherms fail to conform to expectations, and attributed this to ectotherms possessing characteristics that weaken any allometric constraints associated with diving (e.g., the ability to use aquatic respiration to supplement oxygen stores, and to enter thermally-induced hypo-metabolic states, to extend dives) (Brischoux et al. 2008; Campbell et al. 2010). In the case of aquatic respiration, some air-breathers may respire in water using lungs, whereas others may respire through their integument (i. e., "cutaneous respiration"; Lenfant \& Johansen 1972; Feder \& Burggren 1985). Yet, the potentially confounding effects of temperature 
63 on oxygen consumption rates and thus dive duration have not yet been examined in vertebrate

64 ectotherms.

65 Here we present broad-scale analyses of dive duration in both endothermic and

66 ectothermic vertebrates. We compare the predicted body mass and temperature dependence of

67 dive duration based on the oxygen store/usage hypothesis to analyses of extensive empirical data

68 compiled from the literature. The model and results presented here build on previous work in

69 endotherms (Butler \& Jones 1982; Kooyman 1989; Stephens et al. 2008) to examine the

70 relationship in ectotherms, particularly with respect to temperature.

71 We begin by examining the predicted body mass and/or temperature dependence of dive

72 duration based on the oxygen store/usage hypothesis. This hypothesis stipulates that dive

73 duration $\left(t_{D}\right)$ is a function of the total amount of oxygen carried by an organism on its dive $\left(\mathrm{TO}_{2}\right)$

74 divided by the rate at which that oxygen is used (i.e. its metabolic rate, $B$ ) (Butler \& Jones 1982;

75 Kooyman 1989). Thus,

$$
t_{D}=T O_{2} / B
$$

77 where oxygen storage capacity scales approximately linearly with body mass (M) and is

78 independent of temperature (Lindstedt \& Calder 1981; Stephens et al. 2008; Campbell et al.

79 2010) such that:

80

$$
\mathrm{TO}_{2}=a M^{1}
$$

81 , where $a$ is a constant that describes the amount of oxygen that can be stored per gram of body

82 mass (Lindstedt \& Calder 1981; Campbell et al. 2010). Oxygen consumption rate in Eq. 1,

83 however, has both a body mass and temperature dependence such that: 
, where $c$ is a constant describing the amount of oxygen consumed per unit body mass, $d$ describes the scaling of whole organism oxygen consumption rate with body mass $(M)$, and

$87 e^{0.12 \mathrm{Tc}}$ describes the exponential temperature dependence of oxygen consumption rate that is roughly equivalent to a $\mathrm{Q}_{10}$ of 2.5 (Charnov \& Gillooly 2003). Thus, we expect that the oxygen store/usage hypothesis should have both a body mass and temperature dependence such that:

$$
t_{D}=\mathrm{a} \cdot c^{-1} \cdot M^{b-d} \cdot e^{-0.12 \mathrm{Tc}}
$$

91 Note that the body mass dependence of oxygen consumption rate may differ between

92

93

94 endotherms and ectotherms (Gillooly et al. 2016), and thus the body mass dependence of dive duration may also differ. Still, the scaling exponent for whole organism oxygen consumption rate shown in Eq. 4 (i.e., "d") is expected to be close to a value of $3 / 4$ (Isaac \& Carbone 2010) and thus considerably less than the scaling exponent for oxygen storage (i.e., "b") of roughly 1 . The effect of temperature on oxygen consumption rate, though, appears to be more similar in both groups (Gillooly et al. 2001). We evaluate the body mass and temperature dependence of dive duration from Eq. 4 for a diverse assortment of mammals, birds, reptiles, and amphibians (Appendix 1).

\section{Methods}

\section{Data collection}

Data on median and maximum dive duration, body mass, and temperature were obtained from previously published studies for 181 species of endotherms and 29 species of ectotherms (Appendix 1). Leatherback turtles (Dermochelys coriacea) were excluded from consideration since they are functionally endothermic (Penick et al. 1998; Southwood et al. 2005; Bostrom \& 
105 Jones 2007), and direct measures of body temperature were not available. The body temperature

106 of this species may be as much as $18^{\circ} \mathrm{C}$ higher than ambient temperatures (Frair et al. 1972). otherwise we used ambient environmental temperatures as a proxy for body temperatures. For endotherms, we used species-specific measures of body temperatures for mammals and birds when available, or the mean body temperature of species from the same genus (Clarke \& Rothery 2008). If both of these estimates were not available, we used the mean body temperatures of

112 birds $\left(41.5^{\circ} \mathrm{C}\right)$ and mammals $\left(37^{\circ} \mathrm{C}\right)($ Clarke \& Rothery 2008)(Appendix 1$)$. For body mass, we 113 used the values of study subjects, or if unavailable, estimates of adult body masses from other 114 sources (Appendix 1).

\section{Analyses}

We evaluated the body mass and temperature dependence of median and maximum dive duration using Bayesian generalized linear mixed-models (Lunn et al. 2000; Bolker et al. 2009) implemented in R package MCMCglmm (Hadfield 2010). In performing these analyses, we accounted for any non-independence due to shared evolutionary history by including a vertebrate supertree recently constructed by (Gillooly et al. 2016), and by treating species as a random

121 effect. This approach also accounted for effects of species sample sizes. To evaluate statistical

122 models, we calculated conditional $\mathrm{R}^{2}$ values for each model (Nakagawa \& Schielzeth 2013), and

123 assessed model assumptions using diagnostic tests associated with phylogenetic analyses

124 (Paradis et al. 2004; Kembel et al. 2010).

125 To best assess the temperature-dependence of median and maximum dive duration, we 126 first performed analyses on the entire dataset. This dataset includes individuals of the same 
127 species measured at different temperatures. To best assess the mass-dependence of dive duration,

128 we performed an additional set of analyses that was largely restricted to one point per species

129 except when body mass differed substantially between males or females of a species, or between

130 juveniles and adults. For this second set of analyses, median and maximum dive durations were

131 normalized to $30^{\circ} \mathrm{C}$ for all species by assuming a $\mathrm{Q}_{10}$ of 2.5 for oxygen consumption rate

132 (Gillooly et al. 2001; White et al. 2006).

\section{Results and Discussion}

Results show support for the body mass and temperature dependence of dive duration predicted by the oxygen store/usage hypothesis ((Butler \& Jones 1982; Kooyman 1989); Eq. 4). With respect to body mass, analysis of the full dataset showed that median and maximum dive duration increased as a power law with body mass in both ectothermic and endothermic vertebrates (Table 1). While scaling exponents varied from 0.09-0.42 depending on the group in question, for ectotherms the $95 \%$ confidence intervals of these scaling exponents included the 0.25 one would expect for dive duration (Table 1, Eq. 4) based on the linear scaling of oxygen storage and a3/4 power scaling of oxygen consumption rate (Isaac \& Carbone 2010; Gillooly et al. 2016; but see White et al. 2006). In the case of endotherms, however, the confidence limits of these analyses did not include $3 / 4$ (but did include 2/3; Table 1). Still, when the dataset was restricted largely to one point per species, and adjusted to a common temperature, the scaling exponents for median and maximum dive duration ranged from only 0.21 to 0.34 , in closer agreement with expectations from the oxygen store/usage hypothesis and the $3 / 4$ scaling of oxygen consumption (Table 2; Eq. 4). With respect to ectotherms, then, our results differ from previous studies showing no body mass dependence of dive duration (Brischoux et al. 2008; 
150 Campbell et al. 2010). We speculate that this is because we explicitly accounted for the effects of 151 temperature.

152

153

154

155

156

157

158

159

160

161

162

163

164

165

166

167

168

169

170

171

172

A comparison of the body mass-dependence of dive duration in endothermic and ectothermic vertebrates shows both similarities and differences-both of which are qualitatively consistent with the oxygen store/usage hypothesis. First, body mass explained between 63-68 \% in temperature-adjusted median and maximum dive duration in both groups. However, the scaling exponents for these relationships in ectotherms $(0.21,0.22)$ were slightly lower than those of endotherms $(0.31,0.34$; Figure 1 , Table 2$)$. This observation is consistent with work showing that the body mass scaling of oxygen consumption rate is steeper in ectotherms (exponents: 0.84-0.90) than in endotherms $(0.70-0.74)$ (Gillooly et al. 2016). Similarly, the relatively high intercepts of the dive duration-body mass relationships in ectotherms as compared to endotherms are consistent with well-established differences in the oxygen consumption rates of ectotherms and endotherms. On average, whole organism oxygen consumption rates of endothermic vertebrates are approximately 1-2 orders of magnitude higher than ectotherms after accounting for any effects of temperature (Gillooly et al. 2001; Brown et al. 2004). As such, endotherms would be expected to use their oxygen stores more quickly than ectotherms, and have dive durations roughly an order of magnitude lower than ectotherms-as was observed (Fig. 2).

Dive duration was also shown here to vary systematically with temperature (Table 1, Figure 2). Note that while temperature has been shown to affect the dive duration of individual species (Priest \& Franklin 2002; Storch et al. 2005) (, no broad-scale analyses of temperature on dive duration have been previously undertaken. The temperature dependence of the oxygen store/usage hypothesis described by Eq. 4 has not been fully appreciated since the hypothesis has 
173 largely been applied to endotherms. Our results show that, at least in ectotherms, median and

174 maximum dive duration decreases with increasing temperature as $e^{-0.11}$ and $e^{-0.13}$, respectively

175 (Table 1, Figure 2)-similar to that described by Eq. 4. This equates roughly to a $\mathrm{Q}_{10}$ of 2.5 such

176 that dive duration will decrease by roughly 2.5 -fold for every $10^{\circ} \mathrm{C}$ increase in temperature.

177 Thus, increases in environmental temperature could substantially reduce foraging time for

178 ectothermic divers, and thus potentially affect individual fitness and population viability. The

179 effect of any such increase would be most acute at warmer temperatures, where a smaller

180 increase in temperature could have a greater effect on dive duration (see Dillon et al. 2010).

Together, these results point to the utility of the oxygen store/usage hypothesis for explaining some similarities and differences in dive duration among diverse vertebrates. Still, a deliberately simplified model such as this is perhaps most useful as a point of departure for examining species-specific adaptations for diving-both physiological and behavioral. Accounting for the effect of body mass and temperature on dive duration should be helpful in evaluating the benefit of such adaptations. More broadly, the model and results presented here demonstrate how considering the physiological effects of body size and temperature can reveal important insights into behavioral ecology (Hayward, Gillooly, \& Kodric-Brown 2012). 
194 Table 1: Body mass and temperature dependence of dive duration in vertebrates. Outputs

195 from generalized linear mixed-models relating dive duration (median or maximum, in minutes)

196 to body mass (natural log-transformed, in grams) and temperature $\left({ }^{\circ} \mathrm{C}\right)$. Conditional $\mathrm{R}^{2}$ values

197 are reported, along with the slopes and intercepts of the relationships, and the sample sizes $(\mathrm{N}$;

198 with number of species). Results shown here represent the full dataset with multiple individuals

199 for many species.

\begin{tabular}{|c|c|c|c|c|c|c|}
\hline Model & $\begin{array}{l}\text { Resp. } \\
\text { Var. }\end{array}$ & Intercept $(95 \% \mathrm{Cl})$ & $\ln$ (Mass) $(95 \% \mathrm{Cl})$ & Temp. $(95 \% \mathrm{Cl})$ & $\mathrm{R}^{2}$ & $\mathrm{~N}$ (species) \\
\hline \multirow[t]{2}{*}{ Ectotherms } & Med. & $4.00(1.78,5.83)$ & $0.19(0.06,0.32)$ & $-0.13(-0.16,-0.09)$ & 0.72 & $267(29)$ \\
\hline & Max. & $5.88(3.42,8.21)$ & $0.09(-0.09,0.26)$ & $-0.11(-0.13,-0.09)$ & 0.81 & $267(29)$ \\
\hline \multirow[t]{2}{*}{ Endotherms } & Med. & $-1.65(-7.51,3.79)$ & $0.42(0.35,0.49)$ & $-0.06(-0.20,0.08)$ & 0.72 & 738 (181) \\
\hline & Max. & $0.52(-4.71,6.37)$ & $0.34(0.30,0.42)$ & $-0.07(-0.21,0.07)$ & 0.62 & $738(181)$ \\
\hline \multirow[t]{2}{*}{ All } & Med. & $2.34(0.94,3.82)$ & $0.37(0.31,0.42)$ & $-0.14(-0.16,-0.11)$ & 0.38 & 1005 (210) \\
\hline & Max. & $3.34(1.98,4.56)$ & $0.32(0.27,0.38)$ & $-0.12(-0.14,-0.10)$ & 0.28 & $1005(210)$ \\
\hline
\end{tabular}

200

201

202

203

204

205

206

207 
209 Table 2: Body mass dependence of temperature-adjusted dive duration in vertebrates.

210 Outputs from generalized linear mixed-models relating temperature-adjusted dive duration

211 (median or maximum) to body mass (ln-transformed, in grams) for ectothermic (amphibians and

212 reptiles) and endothermic (mammals and birds) vertebrates. Conditional $\mathrm{R}^{2}$ values are reported,

213 along with the slopes and intercepts of the relationships, and sample sizes $(\mathrm{N}$; with number of

214 species).

\begin{tabular}{llcccc}
\hline \multirow{2}{*}{ Model } & $\begin{array}{l}\text { Res. } \\
\text { Var. }\end{array}$ & Intercept $(95 \%)$ & $\ln ($ Mass $)(95 \% \mathrm{Cl})$ & $\mathrm{R}^{2}$ & $\mathrm{~N}$ (species) \\
\hline \multirow{2}{*}{ Ectotherms } & Med. & $0.12(-1.88,2.34)$ & $0.22(0.02,0.42)$ & 0.68 & $28(28)$ \\
& Max. & $2.05(-2.26,6.36)$ & $0.21(-0.08,0.55)$ & 0.67 & $28(28)$ \\
\multirow{2}{*}{ Endotherms } & Med. & $-2.49(-3.94,-0.90)$ & $0.34(0.23,0.42)$ & 0.63 & $187(165)$ \\
& Max. & $-1.02(-2.51,0.42)$ & $0.31(0.24,0.39)$ & 0.68 & $187(165)$ \\
& Med. & $-1.47(-2.72,-0.26)$ & $0.30(-0.21,0.41)$ & 0.33 & $215(193)$ \\
& Max. & $0.02(-1.30,1.57)$ & $0.31(0.22,0.42)$ & 0.22 & $215(193)$ \\
\hline
\end{tabular}

215 
216 Figure 1: The body mass dependence of dive duration in vertebrates. The natural logarithm

217 of median (left) and maximum dive duration (min.; right) as a function of the natural logarithm

218 of body mass (g) for air-breathing endothermic (birds and mammals; closed points, solid line)

219 and ectothermic vertebrates (reptiles and amphibians; open points, dashed line). Data were

220 normalized to $30{ }^{\circ} \mathrm{C}$ assuming a $\mathrm{Q}_{10}$ of 2.5. Most points represent a single species (see Methods,

221 and Table 2 for statistics).

222

223

224
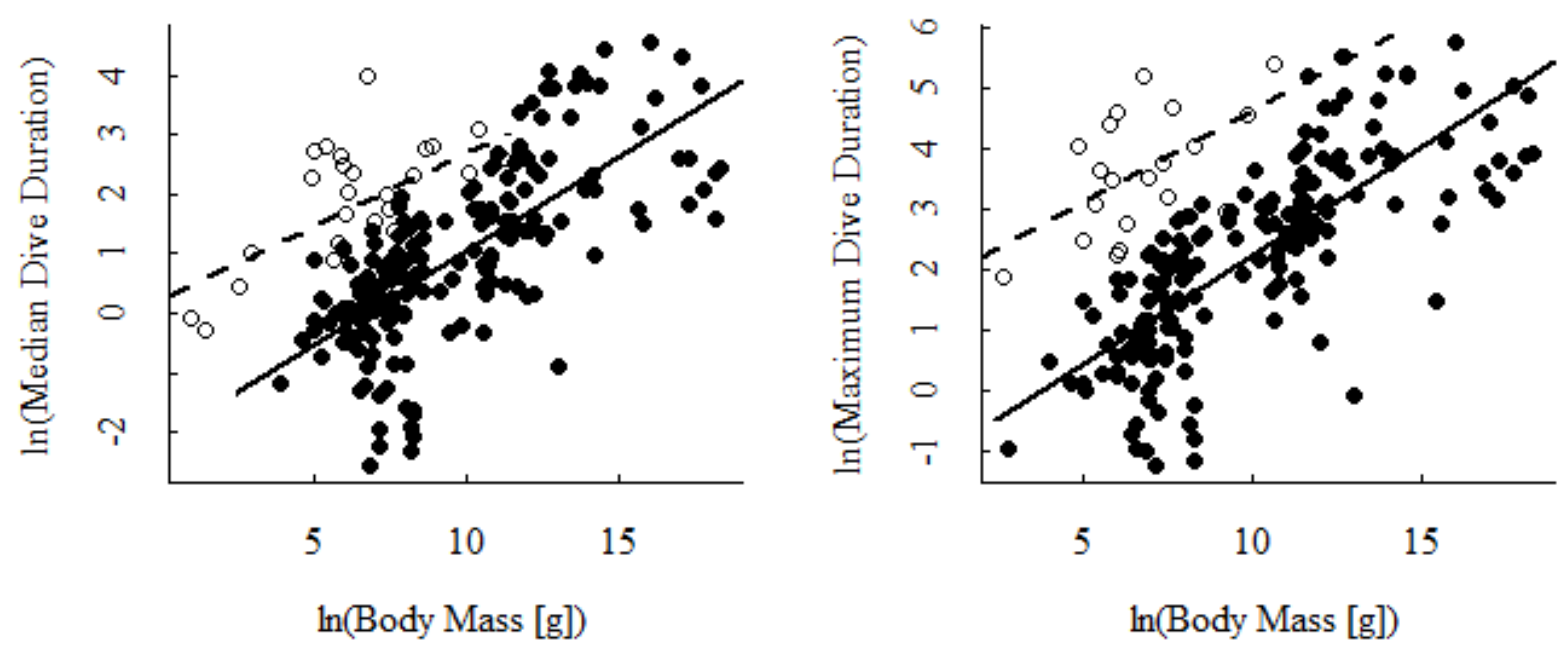

225

226 
228 Figure 2: The temperature dependence of dive duration in vertebrates. The natural

229 logarithm of body mass-corrected median (left) and maximum (right) dive duration as a function

230 of temperature $\left({ }^{\circ} \mathrm{C}\right)$ for endothermic (birds and mammals; closed points) and ectothermic

231 vertebrates (reptiles and amphibians; open points, dashed line). Many species are represented by

232 multiple points, as described in the methods (see Table 1 for statistics).

233

234

235
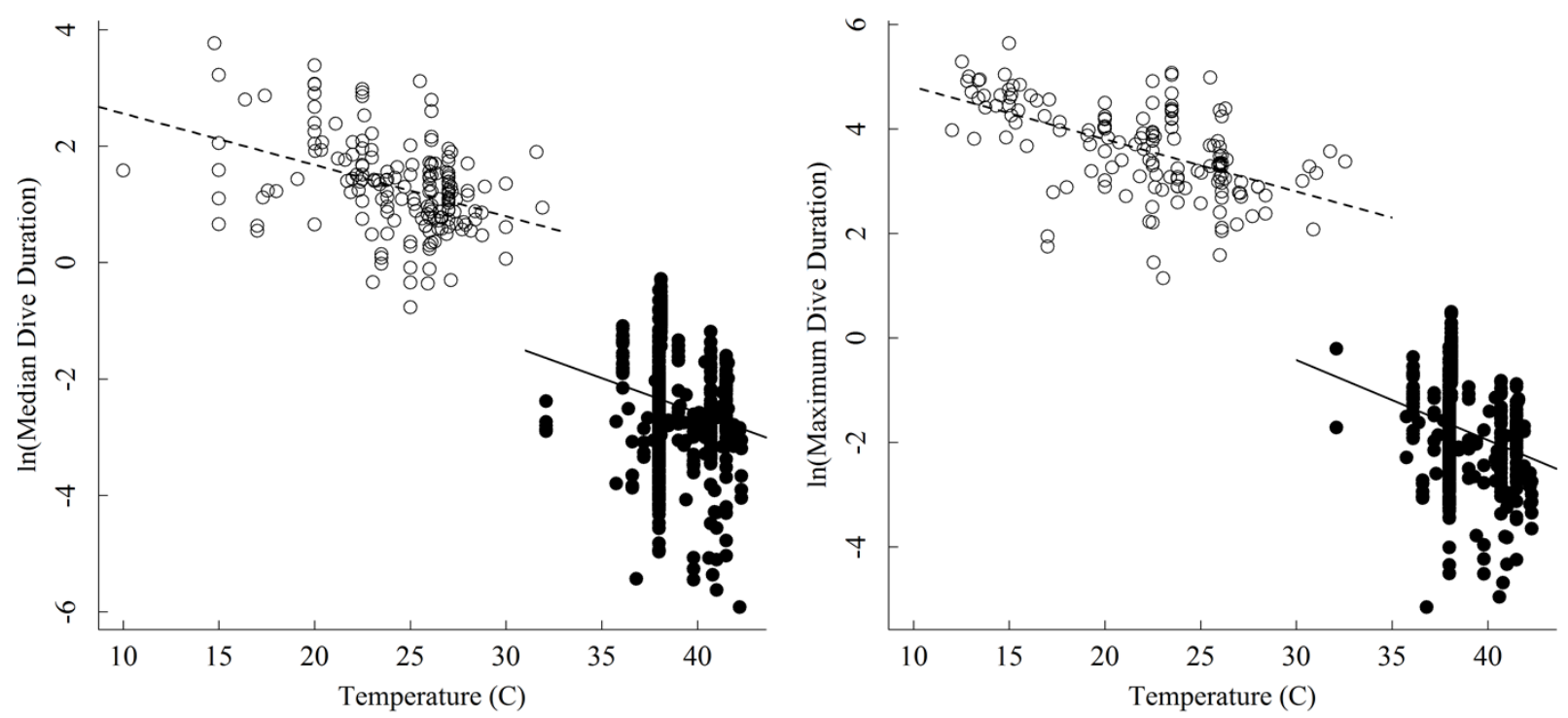

236

237

238

239 
242

243

244

245

246

247

248

249

250

251

252

253

254

255

256

257

258

259

260

261

262

263

264

265

266

267

268

269

270

271

272

Acknowledgements: We thank F. Brischoux and A. Hein for helpful discussions in the early stages of this project. We also thank J. P. Gomez and E. Mavrodiev for their assistance with statistical matters and phylogenetics, and A. Clarke for graciously allowing us to use his dataset.

\section{References}

Andrews RD, and Enstipp MR. 2016. Diving physiology of seabirds and marine mammals: Relevance, challenges and some solutions for field studies. Comparative Biochemistry and Physiology Part A: Molecular \& Integrative Physiology.

Bolker BM, Brooks ME, Clark CJ, Geange SW, Poulsen JR, Stevens MHH, and White J-SS. 2009. Generalized linear mixed models: a practical guide for ecology and evolution. Trends in Ecology \& Evolution 24:127-135.

Bostrom BL, and Jones DR. 2007. Exercise warms adult leatherback turtles. Comparative Biochemistry and Physiology - Part A: Molecular \& Integrative Physiology 147:323-331.

Boyd IL. 1997. The behavioural and physiological ecology of diving. Trends in Ecology \& Evolution 12:213-217.

Brischoux F, Bonnet X, Cook TR, and Shine R. 2008. Allometry of diving capacities: ectothermy vs. endothermy. Journal of Evolutionary Biology 21:324-329.

Brown JH, Gillooly JF, Allen AP, Savage VM, and West GB. 2004. Response to Forum Commentary on "Toward a Metabolic Theory of Ecology". Ecology 85:1818-1821.

Butler PJ, and Jones DR. 1982. The comparative physiology of diving in vertebrates. Advances in Comparative Physiology and Biochemistry 8:179-364.

Butler PJ, and Jones DR. 1997. Physiology of diving of birds and mammals. Physiol Rev 77:837899. 
281

282

283

284

285

286

287

288

289

290

291

292

293

294

295

296

297

298

299

300

301

302

303

304

305

306

307

308

309

310

311

312

313

314

315

316

317

318

Campbell HA, Sullivan S, Read MA, Gordos MA, and Franklin CE. 2010. Ecological and physiological determinants of dive duration in the freshwater crocodile. Functional Ecology 24:103-111.

Charnov E, and Gillooly J. 2003. Thermal time: body size, food quality and the $10{ }^{\circ} \mathrm{C}$ rule. Evolutionary Ecology Research 5:43-51.

Clarke A, and Rothery P. 2008. Scaling of body temperature in mammals and birds. Functional Ecology 22:58-67.

Dillon ME, Wang G, and Huey RB. 2010. Global metabolic impacts of recent climate warming. Nature 467:704-706.

Feder, ME, and Burggren, WW 1985. Cutaneous gas exchange in vertebrates: design, patterns, control and implications. Biological Reviews 60(1): 1-45.

Frair W, Ackman RG, and Mrosovsky N. 1972. Body Temperature of Dermochelys coriacea: Warm Turtle from Cold Water. Science 177:791-793.

Gillooly JF, Brown JH, West GB, Savage VM, and L. CE. 2001. Effects of size and temperature on metabolic rate. Science 293:2248-2251.

Gillooly JF, Gomez JP, Mavrodiev EV, Rong Y, and McLamore ES. 2016. Body mass scaling of passive oxygen diffusion in endotherms and ectotherms. Proceedings of the National Academy of Sciences 113:5340-5345.

Hadfield JD. 2010. MCMC methods for multi-response generalized linear mixed models: the MCMCglmm R package. Journal of Statistical Software 33:1-22.

Halsey LG, Blackburn TM, and Butler PJ. 2006a. A comparative analysis of the diving behaviour of birds and mammals. Functional Ecology 20:889-899.

Halsey LG, Butler PJ, and Blackburn TM. 2006b. A phylogenetic analysis of the allometry of diving. The American naturalist 167:276-287.

Hayward A, Gillooly JF, and Kodric-Brown AB. 2012. Behavior, In, Metabolic Ecology: A Scaling Approach, Eds. Sibly RM and Brown JH. University of Chicago Press. 67-77.

Isaac NJ, and Carbone C. 2010. Why are metabolic scaling exponents so controversial? Quantifying variance and testing hypotheses. Ecology Letters 13(6): 728-735.

Kembel SW, Cowan PD, Helmus MR, Cornwell WK, Morlon H, Ackerly DD, Blomberg SP, and Webb CO. 2010. Picante: R tools for integrating phylogenies and ecology. Bioinformatics 26:1463-1464.

Kooyman GL. 1989. Diverse divers: physiology and behavior. Berlin: Springer-Verlag. 
319

320

321

322

323

324

325

326

327

328

329

330

331

332

333

334

335

336

337

338

339

340

341

342

343

344

345

346

347

348

349

350

351

352

353

354

355

356

357

358

359

360

361

362

363

364

Kooyman GL, and Ponganis PJ. 1998. The physiological basis of diving to depth: Birds and Mammals. Annual Review of Physiology 60:19-32.

Lenfant C, and Johansen K. 1972. Gas exchange in gill, skin, and lung breathing. Respiration Physiology, 14(1): 211-218.

Lindstedt SL, and Calder WA, III. 1981. Body Size, Physiological Time, and Longevity of Homeothermic Animals. The Quarterly Review of Biology 56:1-16.

Lunn DJ, Thomas A, Best N, and Spiegelhalter D. 2000. WinBUGS-a Bayesian modelling framework: concepts, structure, and extensibility. Statistics and Computing 10:325-337.

Mirceta S, Signore AV, Burns JM, Cossins, AR, Campbell, KL, and Berenbrink, M. 2013. Evolution of mammalian diving capacity traced by myoglobin net surface charge. Science 340(6138): 1234192.

Nakagawa S, and Schielzeth H. 2013. A general and simple method for obtaining R2 from generalized linear mixed-effects models. Methods in Ecology and Evolution 4:133-142.

Paradis E, Claude J, and Strimmer K. 2004. APE: analyses of phylogenetics and evolution in R language. Bioinformatics 20:289-290.

Penick DN, Spotila JR, O'Connor MP, Steyermark AC, George RH, Salice CJ, and Paladino FV. 1998. Thermal independence of muscle tissue metabolism in the leatherback turtle, Dermochelys coriacea. Comparative Biochemistry and Physiology - Part A: Molecular \& Integrative Physiology 120:399-403.

Priest TE, and Franklin CE. 2002. Effect of water temperature and oxygen levels on the diving behavior of two freshwater turtles: Rheodytes leukops and Emydura macquarii. Journal of Herpetology:555-561.

Schreer, \#160, F. J, Kovacs, and M. K. 1997. Allometry of diving capacity in air-breathing vertebrates. Ottawa, CANADA: National Research Council of Canada.

Southwood AÂ L, Andrews RÂ D, Paladino FÂ V, and Jones DÂ R. 2005. Effects of Diving and Swimming Behavior on Body Temperatures of Pacific Leatherback Turtles in Tropical Seas. Physiological and Biochemical Zoology 78:285-297.

Stephens PA, Carbone C, Boyd IL, McNamara JM, Harding KC, and Houston AI. 2008. The Scaling of Diving Time Budgets: Insights from an Optimality Approach. The American Naturalist 171:305-314.

Storch S, Wilson RP, Hillis-Starr Z-M, and Adelung D. 2005. Cold-blooded divers: temperaturedependent dive performance in the wild hawksbill turtle Eretmochelys imbricata. Marine Ecology Progress Series 293:263-271. 
365 White CR, Phillips NF, and Seymour RS. 2006. The scaling and temperature dependence of 366 vertebrate metabolism. Biology Letters 2:125-127.

367 